\title{
Crystal critters
}

\author{
Samantha A. McBride $\odot$, Henri-Louis Girard $\odot$, and Kripa K. Varanasi* \\ Massachusetts Institute of Technology, Department of Mechanical Engineering, 77 Massachusetts Ave, \\ Cambridge, Massachusetts 02141, USA
}

(Received 6 August 2020; published 12 November 2020)

\begin{abstract}
This paper is associated with a video winner of a 2019 American Physical Society's Division of Fluid Dynamics (DFD) Milton van Dyke Award for work presented at the DFD Gallery of Fluid Motion. The original video is available online at the Gallery of Fluid Motion, https://doi.org/10.1103/APS.DFD.2019.GFM.V0040.
\end{abstract}

DOI: 10.1103/PhysRevFluids.5.110508

The coupled effects between fluid flow and mineral precipitation lead to the formation of some of nature's most spectacular structures including patterned stalactites [1], stalagmites, crystal caves [2], and travertines. In these macroscopic geophysical examples, fluid flow and mineral growth have exceedingly large timescales spanning decades to centuries. Here, we introduce an unexpected consequence of the combined effects of evaporative flow, nanoscale confinement, and precipitation in which unique microscopic crystal structures form from evaporating drops in a matter of minutes. We name these crystal structures "crystal critters" because of their lifelike growth and appearance.

To form crystal critters, a drop of water containing sodium chloride dissolved to its solubility limit is placed on a heated, nanotextured superhydrophobic surface; as shown in Fig. 1(a). The drop begins to evaporate due to heat transfer from the hot substrate to the fluid. Volumetric losses of water create supersaturated conditions for the salt so that crystals begin to precipitate at the air/water interface. A globelike structure composed of halite crystals forms during this initial phase. At some point during evaporation, the weight of the water sufficiently reduces, and the surface area of the salt globe sufficiently increases, so that the force of surface tension exceeds gravity. At this moment, the remaining water dewets from the underlying superhydrophobic substrate in favor of wetting the newly formed hydrophilic halite globe instead. This moment is readily visible during critter formation [see the third and fourth panels of Fig. 1(a)].

After dewetting, fluid/substrate contact points are limited to just a few locations where the crystal structure balances on the substrate. It is at these points where fluid contacts the hot substrate where the majority of evaporation occurs for the remainder of the process. Evaporative flows directed towards the substrate transport dissolved salt towards the contact points, which then forces crystallization into a tubelike structure. The continuous process of evaporation between the structure and substrate and crystallization at these points enables growth of the tubelike critter legs. Growth is terminated once fluid has completely evaporated.

Crystal critters can form a number of different shapes, as shown in Fig. 1(b). The exact morphology of a given critter is random, as one cannot predict how the crystal globes will form

\footnotetext{
*Corresponding author: varanasi@mit.edu
}

Published by the American Physical Society under the terms of the Creative Commons Attribution 4.0 International license. Further distribution of this work must maintain attribution to the author(s) and the published article's title, journal citation, and DOI. 

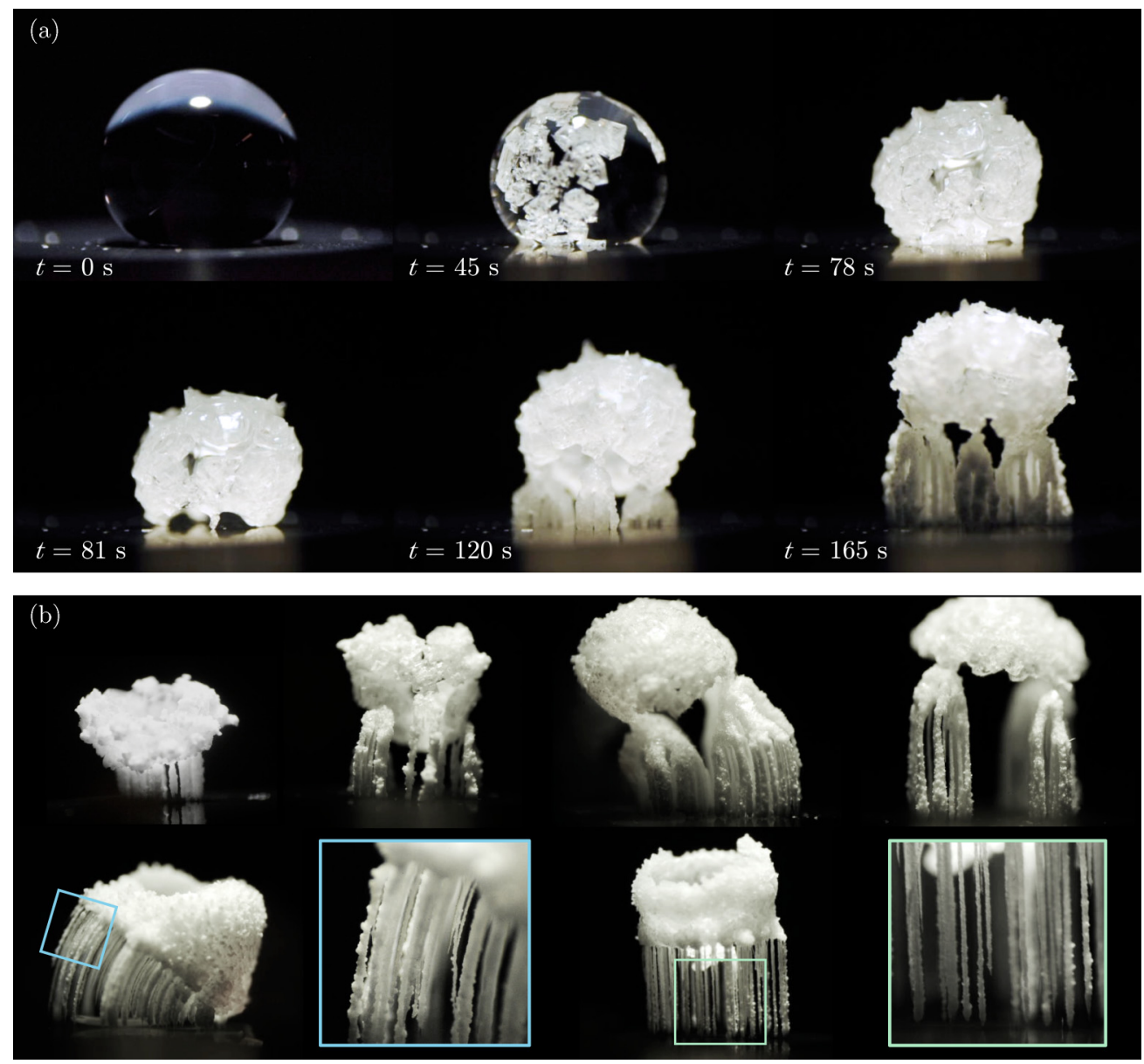

FIG. 1. (a) Time series of the growth of a crystal critter starting from placement of the 5- $\mu \mathrm{L}$ saline water drop on the hot superhydrophobic surface, and progressing through the formation of the salt globe, lift-off of the globe from the surface, formation of the legs, and final crystal critter salt structure. Video sequence of this process can be found at https://doi.org/10.1103/APS.DFD.2019.GFM.V0040. (b) Photographs showing a myriad of crystal critter structures formed via the same process. Bottom panel insets show close-up images of the crystal legs.

during the first phase nor where the contact points between the critter and substrate will be. We have observed critters with dozens of legs, while others have only a handful (which may break under the weight of the fluid/crystal mass). Critters that roll or fall over before complete evaporation will form new legs at their new location and continue growth until evaporation ceases.

The length scale of the superhydrophobic texture is critical to the critter phenomenon, as saline drops evaporated on superhydrophobic surfaces with microscale features are subject to crystal inclusion into the texture [3]. The formation of hydrophilic crystals within the texture leads to horizontal growth and prevents the dewetting phenomena that leads to leg formation. Thus, crystal structures formed on microtextured superhydrophobic surfaces take the form of rings or globes [4]. In contrast, on the nanotextured superhydrophobic surfaces used here, crystals are unable to grow into the texture due to confinement. Similar observations have been made for ice crystallization, where nanotextured surfaces prevented frost formation, whereas microtextures did not [5]. 
In addition to being visually striking and unusual, the crystal critter phenomenon has potential applications for antifouling heat transfer materials due to the exceedingly low adhesion between crystals and substrates.

The authors are grateful for funding support from Equinor via the MIT Energy Initiative. S.A.M. is grateful to acknowledge funding from the MIT Martin Fellowship Program and from the NSF GRFP Grant No. 1122374.

[1] P. Y. Chan and N. Goldenfeld, Steady states and linear stability analysis of precipitation pattern formation at geothermal hot springs, Phys. Rev. E 76, 046104 (2007).

[2] J. M. García-Ruiz, R. Villasuso, C. Ayora, A. Canals, and F. Otálora, Formation of natural gypsum megacrystals in Naica, Mexico, Geology 35, 327 (2007).

[3] S. A. McBride, S. Dash, and K. K. Varanasi, Evaporative crystallization in drops on superhydrophobic and liquid-impregnated surfaces, Langmuir 34, 12350 (2018).

[4] B. Shin, M.-W. Moon, and H.-Y. Kim, Rings, igloos, and pebbles of salt formed by drying saline drops, Langmuir 30, 12837 (2014).

[5] S. Bengaluru Subramanyam, V. Kondrashov, J. Rühe, and K. K. Varanasi, Low ice adhesion on nanotextured superhydrophobic surfaces under supersaturated conditions, ACS Appl. Mater. Interfaces 8, 12583 (2016). 